Fixed Point Theory, 23(2022), No. 1, 127-142

DOI: $10.24193 /$ fpt-ro.2022.1.08

http://www.math.ubbcluj.ro/ nodeacj/sfptcj.html

\title{
EXISTENCE OF MULTIPLE POSITIVE SOLUTIONS TO THE CAPUTO-TYPE NONLINEAR FRACTIONAL DIFFERENTIAL EQUATION WITH INTEGRAL BOUNDARY VALUE CONDITIONS
}

\author{
MD. ASADUZZAMAN* AND MD. ZULFIKAR ALI** \\ *Department of Mathematics, Islamic University, Kushtia-7003, Bangladesh \\ E-mail: masad_iu_math@yahoo.com \\ ** Department of Mathematics, University of Rajshahi, Rajshahi-6205, Bangladesh \\ E-mail: alimath1964@gmail.com
}

\begin{abstract}
In this article, the existence criteria of at least one or at least three positive solutions to the Caputo-type nonlinear fractional differential equation with integral boundary value conditions has been established. The method applied in this study is formulated by the well-known GuoKrasnoselskii's fixed point theorem and Leggett-Williams fixed point theorem. First, the Green's function for corresponding linear fractional differential equation of the main nonlinear fractional differential equation under same boundary value conditions has been constructed. Next, several essential properties of that Green's function have been proved. Finally, in cone spaces some new existence and multiplicity results for the Caputo-type nonlinear fractional differential equation with integral boundary value conditions are obtained. To support the analytic proof appropriate illustrative examples has also been discussed.

Key Words and Phrases: Caputo-type nonlinear fractional differential equation, integral boundary value condition, positive solution, Guo-Krasnoselskii's fixed point theorem, Leggett-Williams fixed point theorem.
\end{abstract}

2020 Mathematics Subject Classification: 34A08, 34B10, 34B15, 47H10.

\section{ACKNOWLEDGMEnT.}

The authors would like to express their special thanks to the honorable reviewers for their valuable comments and suggestions which help to enrich the quality of this article. The authors are also thankful to the journal authority for their unconditional support.

\section{REFERENCES}

[1] B. Ahmad, A. Alsaedi, B. Alghamdi, Analytic approximation of solutions of the forced Duffing equation with integral boundary conditions, Nonlinear Anal. Real World Appl., 9(2008), 17271740.

[2] B. Ahmad, J.J. Nieto, Existence results for nonlinear boundary value problems of fractional integro-differential equations with integral boundary conditions, Bound. Value Probl., 2009(2009), 11 pages. 
[3] M. Asaduzzaman, M.Z. Ali, Existence of positive solution to the boundary value problems for coupled system of nonlinear fractional differential equations, AIMS Mathematics, 4(3)(2019), 880-895.

[4] Z. Bai, On positive solutions of a nonlocal fractional boundary value problem, Nonlinear Anal. Theory Methods Appl., 72(2)(2010), 916-924.

[5] C. Bai, Impulsive periodic boundary value problems for fractional differential equation involving Riemann-Liouville sequential fractional derivative, J. Math. Anal. Appl., 384(2011), 211-231.

[6] A. Cabada, G. Wang, Positive solutions of nonlinear fractional differential equations with integral boundary value conditions, J. Math. Anal. Appl., 389(2012), 403-411.

[7] J. Caballero, I. Cabrera, K. Sadarangani, Positive solutions of nonlinear fractional differential equations with integral boundary value conditions, Abst. Appl. Anal., 2012(2012), 11 pages.

[8] Y. Cu, W. Ma, Q. Sun, X. Su, New uniqueness results for boundary value problem of fractional differential equation, Nonlinear Anal.: Modelling and Control, 23(1)(2018), 31-39.

[9] Y. Cui, Uniqueness of solution for boundary value problems for fractional differential equations, Appl. Math. Lett., 51(2016), 48-54.

[10] Y. Cui, Q. Sun, X. Su, Monotone iterative technique for nonlinear boundary value problems of fractional order $p \in(2,3]$, Adv. Differ. Equ, 2017(1)(2017), Art. ID 248.

[11] F.H. Damag, A. Kilicman, A.T. Al-Arioi, On hybrid type non-linear fractional integrodifferential equations, Mathematics, 8(6)(2020), 984.

[12] F.H. Damag, A. Kilicman, H. Dutta, R.W. Ibrahim, A note on the lower and upper solutions of hybrid-type iterative fractional differential equations, Natl. Acad. Sci. Lett., 43(3)(2020), $277-281$.

[13] K. Diethelm, The Analysis of Fractional Differential Equations, Springer, 2010.

[14] M. Fréchet, Sur quelques points du calcul fonctionnel, Rend. Circ. Mat. Palermo, 22(1906), $1-74$.

[15] E. Girejko, D. Mozyrska, M. Wyrwas, A sufficient condition of viability for fractional differential equations with the Caputo derivative, J. Math. Anal. Appl., 381(2011), 146-154.

[16] J.R. Graef, L. Kong, Positive solutions for a class of higher order boundary value problems with fractional q-derivatives, Appl. Math. Comput., 218(19)(2012), 9682-9689.

[17] D. Guo, V. Lakshmikantham, Nonlinear Problems in Abstract Cones, Academic Press, New York, 1988.

[18] L. Guo, L. Liu, Y. Wu, Existence of positive solutions for singular fractional differential equations with infinite-point boundary conditions, Lithuanian Association of Nonlinear Analysis. Nonlinear Anal.: Modelling and Control, 21(5)(2016), 635-650.

[19] N. Heymans, I. Podlubny, Physical interpretation of initial conditions for fractional differential equations with Riemann-Liouville fractional derivatives, Rheol. Acta, 45(5)(2006), 765-772.

[20] T. Jankowski, Positive solutions for fourth-order differential equations with deviating arguments and integral boundary conditions, Nonlinear Anal., 73(2010), 1289-1299.

[21] J.Q. Jiang, L.S. Liu, Y.H. Wu, Second-order nonlinear singular Sturm-Liouville problems with integral boundary conditions, Appl. Math. Comput., 215(2009), 1573-1582.

[22] D. Jiang, C. Yuan, The positive properties of the Green function for Dirichlet-type boundary value problems of nonlinear fractional differential equations and its application, Nonlinear Anal. Theory Methods Appl., 72(2)(2010), 710-719.

[23] A.A. Kilbas, H.M. Srivastava, J.J. Trujillo, Theory and Applications of Fractional Differential Equations, vol. 204 of North-Holland Mathematics Studies, Elsevier Science B.V., Amsterdam, The Netherlands, 2006.

[24] V. Lakshmikantham, S. Leela, J.V. Devi, Theory of Fractional Dynamic Systems, Cambridge Academic Publishers, Cambridge, UK, 2009.

[25] R.W. Leggett, L.R. Williams, Multiple positive fixed points of nonlinear operators on ordered Banach spaces, Indiana Univ. Math. J., 28(1979), 673-688.

[26] L. Liu, H. Li, C. Liu, Y. Wu, Existence and uniqueness of positive solutions for singular fractional differential systems with coupled integral boundary conditions, J. Nonlinear Sci. Appl., 10(1)(2017), 243-262. 
[27] D.-X. Ma, Positive solutions of multi-point boundary value problem of fractional differential equation, Arab J. Math. Sci., 21(2)(2015), 225-236.

[28] W. Ma, S. Meng, Y. Cui, Resonant integral boundary value problems for Caputo fractional differential equations, Math. Probl. Eng., 2018(2018), Art. ID 5438592, 8 pages.

[29] I. Podlubny, Fractional Differential Equations, Math. Sci. Eng., Academic Press, New York, 1999.

[30] T. Qi, Y. Liu, Y. Cui, Existence of solutions for a class of coupled fractional differential systems with nonlocal boundary conditions, J. Funct. Spaces, 2017(2017), Art. ID 6703860.

[31] T. Qi, Y. Liu, Y. Zou, Existence result for a class of coupled fractional differential systems with integral boundary value conditions, J. Nonlinear Sci. Appl., 10(7)(2017), 4034-4045.

[32] J. Sabatier, O.P. Agrawal, J.A.T. Machado, Advances in Fractional Calculus: Theoretical Developments and Applications in Physics and Engineering, Springer, Dordrecht, The Netherlands, 2007.

[33] H.A.H. Salem, Fractional order boundary value problem with integral boundary conditions involving Pettis integral, Acta Math. Sci. Ser. B Engl. Ed., 31(2)(2011), 661-672.

[34] Q. Sun, H. Ji, Y. Cui, Positive solutions for boundary value problems of fractional differential equation with integral boundary conditions, J. Funct. Spaces, 2018(2108), Art. ID 6461930, 6 pages.

[35] S.W. Vong, Positive solutions of singular fractional differential equations with integral boundary conditions, Math. Comput. Model., 57(2013), 1053-1059.

[36] Y. Wang, L. Liu, Y. Wu, Positive solutions for a class of fractional boundary value problem with changing sign nonlinearity, Nonlinear Anal. Theory Methods Appl., 74(17)(2011), 6434-6441.

[37] Y. Wang, L. Liu, X. Zhang, Y. Wu, Positive solutions of an abstract fractional semi-positone differential system model for bioprocesses of HIV infection, Appl. Math. Comput., 258(2015), $312-324$.

[38] X.M. Zhang, M.Q. Feng, W.G. Ge, Existence result of second-order differential equations with integral boundary conditions at resonance, J. Math. Anal. Appl., 353(2009), 311-319.

[39] D. Zhao, Y. Liu, Positive solutions for a class of fractional differential coupled system with integral boundary value conditions, J. Nonlinear Sci. Appl., 9(5)(2016), 2922-2942.

[40] B. Zhu, L. Liu, Y. Wu, Local and global existence of mild solutions for a class of nonlinear fractional reaction-diffusion equations with delay, Appl. Math. Lett. 61(2016), 73-79.

[41] Y. Zou, G. He, The existence of solutions to integral boundary value problems of fractional differential equations at resonance, J. Funct. Spaces, 2017(2017), Art. ID 2785937, 7 pages.

Received: April 3, 2020; Accepted: October 2, 2020. 